\title{
A Study on The Prevalence of ABO Blood Groups in Malaria Infection
}

\author{
M. H. Shariff and Vineeth G Nair* \\ Department of Pathology, Yenepoya Medical College, Mangalore, Karnataka, India
}

\begin{abstract}
Objectives: To analyse the distribution of blood groups in malaria positive patients in and around the city of Mangalore.

Materials and Methods: This study was conducted from January 2015-December 2015. The study group consisted of malaria positive patients diagnosed by MPFT or MP Smear. Blood grouping, complete blood counts and peripheral smear examinations were done in these patients.

Results: During the 1 year period of our study, there were 278 malaria positive patients. Of the 278 malaria positive cases, $262(94.24 \%)$ cases were P.vivax, $2(0.72 \%)$ were P.falciparum\& 14 (5.04\%) were mixed infections. The vast majority of the patients were male (83.5\%) and the largest number of cases were seen in the $20-29$ age group (39.9\%). The most common peripheral smear finding was thrombocytopenia. 256 (92.1\%) of the patients were Rh positive and only 22 (7.9\%) of cases were Rh negative. The most common ABO blood group seen was O in $38.13 \%$ followed by $\mathrm{B}$ in $28.78 \%$. A blood group had $26.6 \%$ and $\mathrm{AB}$ had only $6.83 \%$. Overall, the most common of the $8 \mathrm{ABO}-\mathrm{Rh}$ groups seen was O positive (35.6\%) followed by B positive $(26.3 \%)$.

Conclusions: In our study, malaria is found to be more prevalent in males, the most common species is P.vivax and most common age group is 20-29yrs. The most common haematological abnormality seen was thrombocytopenia and overall, malaria is seen to occur most in the $\mathrm{O}$ positive blood group which is in concordance with most other studies.
\end{abstract}

Keywords: Malaria, Blood Group, ABO, Rh, Vivax, Falciparum

\section{Introduction}

The ABO system of blood grouping was first discovered and described by Karl Landsteiner in $1900 \cdot{ }^{[1]} \mathrm{He}$ identified three blood groups $\mathrm{A}, \mathrm{B}$ and $\mathrm{O}$. The AB blood group was discovered later, by Decastello and Sturli. ${ }^{[1]}$ In the decades since these discoveries, many studies have been conducted and many research papers written on the possible function(s) of the antigens responsible for $\mathrm{ABO}$ blood grouping. Some argue that these antigens play important roles in the modulation of protein activity, infection and cancer ${ }^{[1]}$ Many infections such as Helicobacter pylori, Neisseria, the smallpox virus, Pasturella pestis etc. have been associated with specific blood group antigens or individuals who are non-secretors. ${ }^{[1]}$

Malaria is one of the oldest killers of man and is caused by an intracellular parasite which is spread by the female Anopheles mosquito. The parasite belongs to the genus Plasmodium which encompasses more than 200 species which infect mammals, birds, and reptiles. ${ }^{[2]}$ Of these, 4 species regularly infect humans. These are Plasmodium vivax, Plasmodium falciparum, Plasmodium malariae and Plasmodium ovale. Recent studies have suggested that Plasmodium ovale malaria in humans is actually caused by two distinct subspecies viz. Plasmodium ovale curtisi named after researcher Christopher F. Curtis and Plasmodium ovale wallikeri named after researcher David Walliker. ${ }^{[3]}$ Another species, Plasmodium knowlesi which primarily affects lower primates but has been known to affect man. ${ }^{[4]}$

In malaria, rosetting is the adherence of Plasmodium infected RBCs to uninfected RBCs. This has been explained by two theories. One states that the phenomenon assists in the propagation of the parasite amongst the RBCs. The other theory states that uninfected cells rosette around an infected RBC and shield it from the host's immune system. Either way, rosette formation is postulated to provide a survival advantage to the parasite. ${ }^{[5]}$

ABO blood group antigens have been linked to the formation of rosettes in malarial infection. ${ }^{[6,7]}$ It has even been theorized that the distribution of $\mathrm{ABO}$ blood groups in the human population is partly due to the selective genetic pressure exerted by Plasmodium falciparum during the course of human evolution. This theory states that the blood group distribution may have been skewed towards the blood groups that would offer a lesser advantage to the parasite. ${ }^{[8]}$ 
In this study, we aim to analyse the distribution of blood groups in malaria positive patients in and around the city of Mangalore.

\section{Materials and Methods}

This was a prospective study conducted at a tertiary care centre in Mangalore for a period of one year from January 2015 to December 2015. The study population comprised of all patients who were diagnosed as being malaria positive via malarial parasite fluorescence test - MPFT (QBC Quantitative Buffy Coat, Becton-Dickinson). These cases were then confirmed by examining 80-100 fields of a thin smear, stained using Leishman's stain, under a 100x oil immersion lens. In the QBC test, approximately 55-65 $\mu \mathrm{L}$ of EDTA anticoagulated blood was collected in the QBC capillary blood tube which was pre-coated with acridine orange. The tube is then closed with a plastic cap on one end and inserting a plastic float into the other. The tube was then centrifuged in the microhematocrit centrifuge at $12000 \mathrm{rpm}$ for 5 minutes. The centrifuged QBC capillary blood tub is then mounted into a Paraviewer tube holder and examined under a UV light source using a 60x oil immersion lens. Parasite density of the blood sample was quantified using a "plus" system.

$$
\begin{array}{lll}
+ & (1+) & =1 \text { parasite per QBC field } \\
++ & (2+) & =1-10 \text { parasites per QBC field } \\
+++ & (3+) & =11-100 \text { parasites per QBC field } \\
++++ & (4+) & =>100 \text { parasites per QBC field }
\end{array}
$$

For all patients who were diagnosed as malaria positive, blood grouping was performed using ERYSCREEN ${ }^{\complement}$ reagent combipack (Tulip Diagnostics Pvt. Ltd.). Complete blood counts were performed using an automated hematology analyser (SYSMEX XS-1000i). Peripheral smear examination was performed on Leishman stained smears.
The collected data was entered in Microsoft Excel 2013, exported to and then analyzed using SPSS version 23 (IBM SPSS Statistics, Chicago, IL). Continuous data was expressed as mean or as median. A confidence interval of $95 \%$ was employed if the distribution was not normal. Statistical evaluation was performed using Chisquare test.

\section{Results}

The study population was composed of 278 malaria positive patients. Of these 278 patients, the predominant species was Plasmodium vivax. The vast majority of patients were male $(83.5 \%)$. The youngest patient was 3 years old and the oldest was 81 years of age. The mean age was 30.50 years (standard deviation $=14.32$ ) and median age was 27 years. The highest number of cases belonged to the 20-29 year age group. There was no statistically significant correlation between age and malarial species (Pearson chi-square value $=17.090, \mathrm{p}=0.251)$. The most common peripheral smear finding was thrombocytopenia which was seen in $92.1 \%$ of cases. A parasite density of +1 was seen in the most number of cases $(49.3 \%)$. The ABO blood group seen to be most predominant amongst the malaria positive patients was found be "O" (38.1\%) and the Rh group seen most was "Rh positive". Thrombocytopenia, unlike hemoglobin values and total leukocyte count, was found to have a statistically significant correlation with malarial species - Plasmodium vivax having the lowest platelet values $(\mathrm{p}<0.001)$. We did not find any statistically significant correlation between parasite density and malarial species (Pearson chi-square value $=4.964, \mathrm{p}=0.548)$, nor did we find any correlation between $\mathrm{ABO}$ blood group and malarial species (Pearson chi-square value $=4.055, \mathrm{p}=0.669)$. The results of the study have been summarised in Tables 1 to 8 .

Table 1: Sex distribution amongst the study population.

\begin{tabular}{|c|c|c|}
\hline Sex & Frequency & Percent \\
\hline Male & 232 & 83.5 \\
\hline Female & 46 & 16.5 \\
\hline Total & $\mathbf{2 7 8}$ & 100 \\
\hline
\end{tabular}

Table 2: Age wise distribution of the different malarial species encountered in the study population.

\begin{tabular}{|c|c|c|c|c|}
\hline \multirow{2}{*}{ Age Groups } & \multicolumn{3}{|c|}{ Species } & Mixed \\
\cline { 2 - 5 } & Vivax & Falciparum & 1 & 10 \\
\hline $\mathbf{0}-\mathbf{9}$ & 8 & 1 & 2 & 47 \\
\hline $\mathbf{1 0 - 1 9}$ & 45 & 0 & 6 & 111 \\
\hline $\mathbf{2 0}-\mathbf{2 9}$ & 105 & 0 & 2 & 41 \\
\hline $\mathbf{3 0}-\mathbf{3 9}$ & 38 & 1 & 2 & 29 \\
\hline $40-49$ & 27 & 0 & 2 & 2 \\
\hline
\end{tabular}




\begin{tabular}{|c|c|c|c|c|}
\hline \multirow{2}{*}{ Age Groups } & \multicolumn{3}{|c|}{ Species } & Mixed \\
\cline { 2 - 5 } & Vivax & Falciparum & 1 & 28 \\
\hline $\mathbf{5 0}-\mathbf{5 9}$ & 27 & 0 & 0 & 9 \\
\hline $\mathbf{6 0}-\mathbf{6 9}$ & 9 & 0 & 0 & 3 \\
\hline Total & 3 & 0 & $\mathbf{1 4}(\mathbf{5 \% )}$ & $\mathbf{2 7 8 ( 1 0 0 \% )}$ \\
\hline
\end{tabular}

Pearson chi-square value $=17.090, p=0.251$ ( $p$ value $<0.05$ is significant)

Table 3: Frequency of the different categories of parasite density.

\begin{tabular}{|c|c|c|}
\hline Parasite Density & Frequency & Percent \\
\hline $\mathbf{1 +}$ & 137 & 29.3 \\
\hline $\mathbf{2 +}$ & 72 & 25.9 \\
\hline $\mathbf{3 +}$ & 57 & 20.5 \\
\hline $\mathbf{4 +}$ & 12 & 4.3 \\
\hline Total & $\mathbf{2 7 8}$ & $\mathbf{1 0 0}$ \\
\hline
\end{tabular}

Table 4: Difference in $\mathrm{Hb}$, Total leukocyte count and platelet count amongst different species.

\begin{tabular}{|c|c|c|c|}
\hline Hematological Parameter & Species & Mean \pm SD & $p$ value \\
\hline \multirow{3}{*}{ Hemoglobin (g/dL) } & Vivax & $12.74 \pm 2.08$ & \multirow{3}{*}{0.106} \\
\hline & Falciparum & $10 \pm 1.41$ & \\
\hline & Mixed & $12.09 \pm 2.68$ & \\
\hline \multirow{3}{*}{ 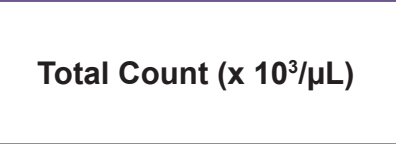 } & Vivax & $5.98 \pm 2.54$ & \multirow{3}{*}{0.06} \\
\hline & Falciparum & $9.45 \pm 3.46$ & \\
\hline & Mixed & $6.97 \pm 3.17$ & \\
\hline \multirow{3}{*}{ 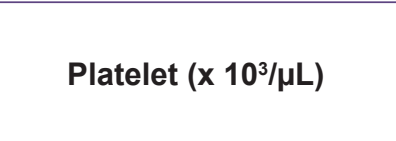 } & Vivax & $93.01 \pm 63.06$ & \multirow{3}{*}{$<0.001$} \\
\hline & Falciparum & $274.5 \pm 252.44$ & \\
\hline & Mixed & $116.93 \pm 111.03$ & \\
\hline
\end{tabular}

$p$ value $<0.05$ is significant

Table 5: Distribution of the different categories of parasite density amongst the different malarial species encountered in the study population.

\begin{tabular}{|c|c|c|c|c|}
\hline \multirow{2}{*}{ Parasite Density } & \multicolumn{3}{|c|}{ Species } & Mixed \\
\cline { 2 - 5 } & Vivax & Falciparum & 9 & 137 \\
\hline $\mathbf{1 +}$ & 128 & 0 & 4 & 72 \\
\hline $\mathbf{2 +}$ & 67 & 1 & 1 & 57 \\
\hline $\mathbf{3 +}$ & 55 & 1 & 0 & 12 \\
\hline $\mathbf{4 +}$ & 12 & 0 & $\mathbf{1 4}$ & $\mathbf{2 7 8}$ \\
\hline Total & $\mathbf{2 6 2}$ & $\mathbf{2}$ & & \\
\hline
\end{tabular}

Pearson chi-square value $=4.964, p=0.548$ ( $p$ value $<0.05$ is significant $)$

Table 6: Frequency of the ABO \& Rh blood groups in the study population

\begin{tabular}{|c|c|c|c|}
\hline \multirow{4}{*}{$\begin{array}{c}* \\
\text { ABO Blood Grouping } \\
\text { System }\end{array}$} & ABO Blood Groups & Frequency & Percent \\
\cline { 2 - 4 } & A & 73 & 26.26 \\
\cline { 2 - 4 } & B & 19 & 6.83 \\
\cline { 2 - 4 } & $\mathbf{0}$ & 80 & 28.78 \\
\cline { 2 - 4 } & Total & 106 & 38.13 \\
\hline
\end{tabular}




\begin{tabular}{|c|c|c|c|}
\hline & ABO Blood Groups & Frequency & Percent \\
\hline \multirow{4}{*}{ Rh Blood Grouping System } & Rh Groups & Frequency & Percent \\
\cline { 2 - 4 } & Positive & 256 & 92.1 \\
\cline { 2 - 4 } & Negative & 22 & 7.9 \\
\cline { 2 - 4 } & Total & 278 & 100 \\
\hline
\end{tabular}

Table 7: Distribution of the different ABO blood groups amongst the different malarial species encountered in the study population.

\begin{tabular}{|c|c|c|c|c|}
\hline \multirow{2}{*}{ ABO Blood Group } & \multicolumn{3}{|c|}{ Species } & \multirow{2}{*}{ Total } \\
\cline { 2 - 5 } & Vivax & Falciparum & 5 & 73 \\
\hline A & 67 & 1 & 2 & 19 \\
\hline AB & 17 & 0 & 2 & 80 \\
\hline B & 78 & 0 & 5 & 106 \\
\hline O & 100 & 1 & $\mathbf{1 4}$ & $\mathbf{2 7 8}$ \\
\hline
\end{tabular}

Pearson chi-square value $=4.055, p=0.669$ ( $p$ value $<0.05$ is significant $)$

Table 8: Distribution of the different categories of parasite density amongst the different ABO blood groups in the study population.

\begin{tabular}{|c|c|c|c|c|c|}
\hline \multirow{2}{*}{ Parasite Density } & \multicolumn{4}{|c|}{ ABO Blood Group } & \multirow{2}{*}{ Tota } \\
\hline & A & AB & B & 0 & \\
\hline $1+$ & 37 & 11 & 39 & 50 & 137 \\
\hline $2+$ & 16 & 3 & 21 & 32 & 72 \\
\hline $3+$ & 16 & 5 & 19 & 17 & 57 \\
\hline 4+ & 4 & 0 & 1 & 7 & 12 \\
\hline Total & 73 & 19 & 80 & 106 & 278 \\
\hline
\end{tabular}

Pearson chi-square value $=8.272, p=0.507$ ( $p$ value $<0.05$ is significant $)$

Table 9: Comparison of our findings with previously conducted studies.

\begin{tabular}{|c|c|c|c|c|}
\hline \multirow{2}{*}{ Study } & \multicolumn{4}{|c|}{ ABO Blood Group } \\
\hline & A & B & 0 & $A B$ \\
\hline Al-Yaman et al (1995) ${ }^{[9]}$ & 33.20 & 15.02 & 38.34 & 13.44 \\
\hline Fischer et al (1998) ${ }^{[10]}$ & 21.27 & 21.06 & 54.40 & 3.27 \\
\hline Pathirana et al (2005) [11] & 27.16 & 24.28 & 39.92 & 8.64 \\
\hline Rowe et al (2007) ${ }^{[12]}$ & 28.63 & 8.06 & 32.66 & 30.65 \\
\hline Tekeste et al (2010) ${ }^{[13]}$ & 31.90 & 18.10 & 38.10 & 11.90 \\
\hline Akanbi et al (2010) ${ }^{[14]}$ & 16.81 & 18.49 & 64.71 & 0.00 \\
\hline Panda et al (2011) ${ }^{[15]}$ & 19.26 & 40.51 & 32.58 & 7.65 \\
\hline Deepa et al. $(2011)^{[16]}$ & 22.00 & 42.00 & 35.00 & 1.00 \\
\hline Tewodros et al. $(2011)^{[17]}$ & 23.50 & 21.90 & 51.30 & 3.30 \\
\hline Gupte et al. $(2012)^{[18]}$ & 24.60 & 35.50 & 30.00 & 8.90 \\
\hline FD Olajevwo et al. (2013) ${ }^{[19]}$ & 34.60 & 23.10 & 38.40 & 3.90 \\
\hline Gayatri et al. (2013) ${ }^{[20]}$ & 16.09 & 40.90 & 34.16 & 8.78 \\
\hline Singh et al. $(2015)^{[21]}$ & 26.30 & 23.60 & 42.10 & 8.00 \\
\hline Tela et al. (2015) [22] & 14.15 & 21.70 & 53.57 & 10.38 \\
\hline Bamou et al. (2016) ${ }^{[23]}$ & 22.22 & 22.22 & 55.56 & 0.00 \\
\hline Our study & 26.26 & 28.78 & 38.13 & 6.83 \\
\hline
\end{tabular}




\section{Discussion}

Malaria is a serious public health issue in India and also in many other parts of the world. It is therefore important to identify any and all risk factors which may predispose an individual to infection. This becomes especially important in endemic areas such as Mangalore where our study was conducted. As mentioned in the results, the predominant blood group amongst the malaria infected individuals was "O" followed by "B", "A" and "AB" in that order. When comparing our findings with previously done studies (Table 11), we found that this was in concordance with 11 studies where $\mathrm{O}$ was the most affected blood group and in discordance with 4 other studies that had B as the most affected blood group, which in our case was the 2nd most affected. ${ }^{[9-23]}$

The distribution of blood groups in malaria infected patients, as obtained in our study, is actually in concordance with the normal $\mathrm{ABO}$ blood group distribution amongst the normal Indian population. According to a multicentric study conducted by Agarwal et al (2014), the most predominant blood group in India, overall, is "O" followed by "B", "A" and then "AB". ${ }^{[2]]}$ The region wise data for South India shows a similar distribution as the all-India figures. ${ }^{[24]} \mathrm{A}$ study similar to that of Agarwal et al conducted by Rao et al in 2014, but which was limited to Mangalore city in its geographical scope, also showed an ABO blood group distribution with the same order and frequency. ${ }^{[25]}$

Given the long history of malaria in India in general and Mangalore in particular, the results of our study seem to support the hypothesis that malaria confers an evolutionary advantage on $\mathrm{O}$ blood group individuals compared with $\mathrm{A}$, $\mathrm{B}$ or $\mathrm{AB}$ in malaria endemic areas. ${ }^{[8]}$ The exact mechanism behind the relative protection offered by "O" blood group as opposed to "A" blood group is not yet properly understood. Many different studies have come up with varying hypotheses as to why this may be. Some of these include rosette formation, which has been observed more in "A" blood group individuals infected with malaria as compared with those with "O" blood group. ${ }^{[26-34]}$ This higher chance of rosette formation by "A" blood group RBCs have been attributed to many factors which act concurrently. These include the presence of intracellular adhesion molecule1, complement receptor 1 , high levels of von Willebrand factor, CD36 and heparin sulfate like glycosaminoglycan. ${ }^{[17,26,27,29,30,32]}$ Blood group "O" cells lack most of the above-mentioned molecules, which reduces the frequency and stability of rosette formation. ${ }^{[3,35]}$ However, most of the above-mentioned pathology is encountered in
Plasmodium falciparum infections. Studies on the relation between Plasmodium vivax and ABO blood groups are few as many studies concentrate on the relationship between Duffy blood groups and Plasmodium vivax. ${ }^{[36-39]}$

Our study is limited by the fact that the vast majority of cases we encountered were infected by Plasmodium vivax. No other species were represented in a number significant enough to draw any conclusions. This is due to the selective geographical distribution of Plasmodium species in India. We also could not include more factors such as other blood grouping systems (Duffy, Knops etc) HbS, $\mathrm{HbC}$, iron status etc. in our study as well clinical features (eg. severe malaria, malaria with complications). Had we been able to do so, more data could have been generated. Further studies with a wider scope are required to more clearly establish the role of ABO blood groups in malaria, especially Plasmodium vivax malaria, in areas such as Mangalore where this species predominates.

\section{Conclusions}

In our study, malaria is found to be more prevalent in males, the most common species is P.vivax and most common age group is $20-29 \mathrm{yrs}$. The most common haematological abnormality seen was thrombocytopenia and overall, malaria is seen to occur most in the $\mathrm{O}$ positive blood group which is in concordance with most other studies.

\section{Abbreviations and Symbols \\ $\mathrm{CD}$ - Cluster of Differentiation \\ $\mathrm{Hb}-$ Hemoglobin \\ MP - Malarial Parasite \\ MPFT - Malarial Parasite Fluorescence Test}

P.Falciparum - Plasmodium Falciparum

P.Vivax - Plasmodium Vivax

QBC - Quantitative Buffy Coat

\section{Reference}

1. Greenwell P. Blood group antigens: molecules seeking a function? Glycoconj J. 1997;14:159-73.

2. Luo Z, Sullivan S, Carlton J. The biology of Plasmodium vivax explored through genomics. Ann N Y Acad Sci. 2015;1342:53-61.

3. Sutherland C, Tanomsing N, Nolder D, Oguike M, Jennison C, Pukrittayakamee S, et al. Two Nonrecombining Sympatric Forms of the Human Malaria Parasite Plasmodium ovale occur globally. J Infect Dis. 2010;201(10):1544-50.

4. Singh B, Kim Sung L, Matusop A, Radhakrishnan A, Shamsul SS, Cox-Singh J, et al. A large focus of naturally acquired Plasmodium knowlesi infections in human beings. Lancet. 2004;363:1017-24. 
5. Lee W, Malleret B, Lau Y, Mauduit M, Fong M, Cho J et al. Glycophorin C (CD236R) mediates vivax malaria parasite rosetting to normocytes. Blood. 2014;123:e100-9.

6. Barragan A, Kremsner P, Wahlgren M, Carlson J. Blood Group A Antigen Is a Coreceptor in Plasmodium falciparum Rosetting. Infect Immun. 2000;68:2971-5.

7. Thakur A, Verma IC. Malaria and ABO blood groups. Indian J Malariol. 1992;29:241-4.

8. Cserti C, Dzik W. The ABO blood group system and Plasmodium falciparum malaria. Blood. 2007;110:2250-8.

9. Al-Yaman F, Genton B, Mokela D, Raiko A, Kati S, Rogerson S, et al. Human cerebral malaria: lack of significant association between erythrocyte rosetting and disease severity. Trans R Soc Trop Med Hyg. 1995;89:55-8.

10. Fischer PR, Boone P. Short report: Severe malaria associated with blood group. Am J Trop Med Hyg. 1998;58:122-3.

11. Pathirana SL, Alles HK, Bandara S, Phonekyaw M, Perera MK, Wickremasinghe SR, et al. ABO blood group types and protection against severe Plasmodium falciparum malaria. Ann Trop Med Parasitol. 2005;99:119-24.

12. Rowe JA, Handel IG, Thera MA, Deans AM, Lyke KE, Kone $\mathrm{A}$, et al. Blood group $\mathrm{O}$ protects against severe Plasmodium falciparum malaria through the mechanism of reduced rosetting. Proc Natl Acad Sci USA. 2007;104:17471-6.

13. Tekeste Z, Petros B. The ABO blood group and Plasmodium falciparum malaria in Awash, Metehara and Ziway areas, Ethiopia. Malar J. 2010;9:280.

14. Akanbi OM, Badaki JA, Adeniran OY, Olotu OO. Effect of blood group and demographic characteristics on malaria infection, oxidative stress and haemoglobin levels in South Western Nigeria. Africa J Microbiol Res. 2010;4:877-80.

15. Panda A, Panda S, Sahu A, Tripathy R, Ravindran B, Das B. Association of $\mathrm{ABO}$ blood group with severe falciparum malaria in adults: case control study and meta-analysis. Malar J. 2011;10:309.

16. Deepa, Alwar VA, Rameshkumar K, Ross C. ABO blood groups and malaria related clinical outcome. J Vector Borne Dis. 2011;48:7-11.

17. Tewodros Z, Abraham D, Berhanu E. Association of ABO blood group and Plasmodium falciparum malaria in Dore Bafeno Area, Southern Ethiopia. Asian Pac J Trop Biomed. 2011;1:289-94.

18. Gupte SC, Patel AG, Patel TG. Association of ABO groups in malaria infection of variable severity. J Vector Borne Dis. 2012;49:78-81.

19. Otajevwo FD, Igoniwari SF. Malaria Parasitaemia Association with ABO Blood Types among Students of a Private University in Western Delta, Nigeria. Int J Trop Dis Health. 2014;4:540-54.

20. Gayathri BN, Harendra KML, Gomathi N, Jeevan S, Reethesh RP. Relationship between ABO blood groups and malaria with clinical outcome in rural area of South India. Glob J Med Public Health. 2013;2:1-7.
21. Singh G, Urhekar AD, Singh R. A study on correlation of malaria infection with $\mathrm{A}, \mathrm{B}, \mathrm{O}, \mathrm{RH}$ blood group system. J Parasitol Vector Biol. 2015;7:67-73.

22. Tela IA, Modibbo MH, Adamu LH, Taura MG. Prevalence of Malaria Infection Among ABO Blood Groups in Jama'are, Nigeria. RA J Appl Res. 2015;1:255-62.

23. Bamou R, Sevidzem SL. ABO/Rhesus blood group systems and malaria prevalence among students of the University of Dschang, Cameroon. Malar World J. 2016;7:1-4.

24. Agrawal A, Bhattacharya P, Kamath S, Mehta N, Tiwari A, Tulsiani $\mathrm{S}$, et al. $\mathrm{ABO}$ and $\mathrm{Rh}(\mathrm{D})$ group distribution and gene frequency; the first multicentric study in India. Asian J Transfus Sci. 2014;8:121-6.

25. Rao C, Shetty J. Frequency of ABO and Rhesus (D) blood groups in Dakshina Kannada district of Karnataka - a study from rural tertiary care teaching hospital in South India. Nitte Univ J Health Sci. 2014;4:57-60.

26. Lublin DM, Griffith RC, Atkinson JP. Influence of glycosylation on allelic and cell-specific $\mathrm{Mr}$ variation, receptor processing, and ligand binding of the human complement $\mathrm{C} 3 \mathrm{~b} / \mathrm{C} 4 \mathrm{~b}$ receptor. J Biol Chem. 1986;261:5736-44.

27. Carlson J, Holmquist G, Taylor DW, Perlmann P, Wahlgren M. Antibodies to a histidine-rich protein (PfHRP1) disrupt spontaneously formed Plasmodium falciparum erythrocyte rosettes. Proc Natl Acad Sci USA. 1990;87:2511-5.

28. Carlson J, Wahlgren M. Plasmodium falciparum erythrocyte rosetting is mediated by promiscuous lectin-like interactions. J Exp Med. 1992;176:1311-7

29. Chen Q, Heddini A, Barragan A, Fernandex V, Pearce SF, Wahlgren M. The semi-conserved head structure of Plasmodium falciparum erythrocyte membrane protein 1 mediates binding to multiple independent host receptors. J Exp Med. 2000;192:1-9.

30. Chen Q, Schlichtherle M, Wahlgren M. Molecular aspects of severe malaria. Clin Micro Rev. 2000;13:439-50.

31. Lopansri BK, Anstey NM, Weinberg JB, Stoddard GJ, Hobbs MR, Levesque MC, et al. Low plasma arginine concentrations in children with cerebral malaria and decreased nitric oxide production. Lancet. 2003;361:676-8.

32. Jenkins PV, O'Donnell JS. ABO blood group determines plasma von Willebrand factor levels: a biologic function after all? Transfusion. 2006;46:1836-44.

33. Van der Heyde HC, Nolan J, Combes V, Gramaglia I, Grau GE. A unified hypothesis for the genesis of cerebral malaria: sequestration, inflammation and hemostasis leading to microcirculatory dysfunction. Trends Parasitol. 2006;22:503-8

34. Rowe JA, Handel IG, Thera MA, Deans AM, Lyke KE, Kone $\mathrm{A}$, et al. Blood group $\mathrm{O}$ protects against severe Plasmodium falciparum malaria through the mechanism of reduced rosetting. Proc Natl Acad Sci USA. 2007;104:17471-6. 
35. Daniels G. The molecular genetics of blood group polymorphism. Transpl Immunol. 2005; 14:143-53

36. Rowe J, Opi D, Williams T. Blood groups and malaria: fresh insights into pathogenesis and identification of targets for intervention. Curr Opin Hematol. 2009;16:480-7.

37. Culleton R, Ferreira P. Duffy Phenotype and Plasmodium vivax infections in Humans and Apes, Africa. Emerg Infect Dis. 2012;18:1704-5.
38. Menard D, Barnadas C, Bouchier C, Henry-Halldin C, Gray L, Ratsimbasoa A, et al. Plasmodium vivax clinical malaria is commonly observed in Duffy-negative Malagasy people. P Natl Acad Sci USA. 2010;107:5967-71.

39. Gunalan K, Lo E, Hostetler J, Yewhalaw D, Mu J, Neafsey $\mathrm{D}$, et al. Role of Plasmodium vivax Duffy-binding protein 1 in invasion of Duffy-null Africans. P Natl Acad Sci USA. 2016;113:6271-6.

*Corresponding author:

Dr. Vineeth G Nair, Department of Pathology, Yenepoya Medical College, Yenepoya University Campus, Deralakatte, Mangalore, Karnataka - 575018, India Phone: +919972917978

Email: dr.vgn86@gmail.com

Financial or other Competing Interests: None. 